\title{
Influence of long-lasting heat treatments on the structure and properties of the zirconium-steel bond
}

\author{
Mariusz Prażmowski ${ }^{1,{ }^{*}, \text { Henryk } \text { Paul }^{2}, \text { Michał Najwer }}{ }^{1}$, and Anna Pocica ${ }^{1}$ \\ ${ }^{1}$ Opole University of Technology, Faculty of Mechanical Engineering, 5 Mikolajczyka St., Opole, Poland \\ ${ }^{2}$ Polish Academy of Sciences, Institute of Metallurgy and Materials Science, 25 Reymonta St., Krakow, Poland
}

\begin{abstract}
The explosive welding technology is related to the dynamic impact of the clad onto base material. These results in significant microstructural changes of the bonded materials, the increase of internal stresses and the strain hardening of layers near the interface. In order to eliminate these unfavorable effects, it is advisable to carry out proper heat treatment. The paper presents the results of structural examinations and mechanical properties of bimetal zirconium - carbon steel, after longlasting heat treatment. Bimetallic samples were annealed at $600^{\circ} \mathrm{C}$ for $1,10,100,500,1000$ hours. Microscopic examination were used to the analysis of microstructural changes, whereas systematic microhardness measurements and static tensile test to evaluation of the mechanical properties. It was found that the temperature has a beneficial effect on the changes in the bond zone and for longer annealing times a systematic decrease of the strength properties of the tested bimetal was observed. However, essential for the clad mechanical properties changes were observed in carbon steel plate. After short annealing (times of $1 \mathrm{~h}$ and $10 \mathrm{~h}$ ) only small microstructural changes due to processes of recovery and recrystallization were observed in layers near the interface. The increase of annealing time was conducive to grain growth and carbon diffusion in the interfacial layer from steel towards zirconium.
\end{abstract}

\section{Introduction}

The construction of modern and corrosion-resistant chemical and processing apparatus with a planned long service life and relatively low production costs requires reactive metals, such as titanium, zirconium, tantalum and their alloys, to be used. These materials in the form of rolled flat products, i.e. plates or tapes are relatively expensive. The application of layered composites may be a solution to the reduction of their use costs. In such systems the base plate (usually steel of a proper grade) is the material that complies with construction requirements, then on top of it a thin layer of material with special properties (more expensive) is cladded. So far the only technology that enables materials with very different physical and chemical properties to be join together is explosion welding. It enables to achieve adequately high strength parameters of the bond that ensure the wide industrial processing and use of clad elements in all sorts of constructions.

Technological aspects of explosion bonding were demonstrated in many authors' research [1-3]. A distinguishing feature of the technology is joining together materials as a result of the oblique collision of plates at high velocity. Consequently, there is considerable plastic deformation and strengthening of joined materials in layers near the interface. The structural changes that occur in layers near the interface (the weld zone) were described in detail in many earlier publications [1-9]. The strain hardening of these layers and increase of internal stresses are unfavorable from the point of view of further processing of clad, i.e. straightening, drawing and stamping, machining, etc. [10-13]. In this case annealing is an important issue in the clads production. The purposefulness, or even necessity, of carrying out this type of treatment was documented in an earlier works, e.g. [14-17]. In the case of layered materials, the selection of proper annealing parameters constitutes a big technological problem. On the one hand we are dealing with a basic material that requires high temperature and long heat treatment time. On the other hand, the use of reactive material as the overlay layer largely limits these parameters as it is generally sensitive to high temperature oxidation [1819]. What is more, a long-lasting impact of a high temperature under operating conditions does have an effect on the structural changes in the weld zone which most often decreases the strength properties of the clad.

This study presents the results that form the basis for the quality evaluation of zirconium-carbon steel bond achieved with the use of explosion welding. The impact of a long-lasting effect of a high temperature on the structural changes and mechanical properties of zirconium (the flyer plate) and carbon steel (the base plate) plates were analysed. Simulation heat treatments were performed at a temperature of $600^{\circ} \mathrm{C}$ for $1,10,100$, 500 and 1000 hours in vacuum. Based on macro- and microstructural observations, as well as on mechanical properties measurements the effect of heat treatments on

Corresponding author: m.prazmowski@po.opole.pl 
the properties of the zirconium-carbon steel clads, was shown.

\section{Research material and techniques}

The material for this study was produced by means of explosion welding in the form of testing plates with dimensions $300 \times 500 \mathrm{~mm}$. The sheets of steel of $22 \mathrm{~mm}$ thickness (type P355NL2) as the base plate and sheets of Zr700 alloy of $3.15 \mathrm{~mm}$ thickness as a flyer plate were used for the clad preparation. Table 1 present the chemical composition whereas Table 2 the basic mechanical properties of the joined materials in the initial state.

Table 1. Chemical composition (in wt.\%) of carbon steel P355L2N and zirconium $\mathrm{Zr} 700$

\begin{tabular}{|c|c|c|c|}
\hline & Material & Zr 700 & P 355L2N \\
\hline \multirow{14}{*}{ 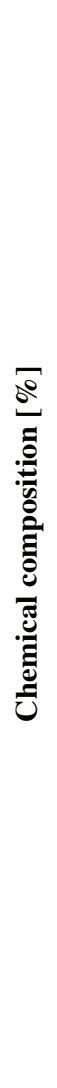 } & C & $<0.002$ & 0.170 \\
\hline & $\mathbf{S i}$ & - & 1.130 \\
\hline & Mn & - & 0.345 \\
\hline & $\mathbf{P}$ & - & 0.008 \\
\hline & $\mathbf{S}$ & - & 0.001 \\
\hline & $\mathbf{N i}$ & - & 0.285 \\
\hline & $\mathrm{Cr}$ & 0.050 & 0.150 \\
\hline & $\mathbf{H}$ & $<0.0003$ & - \\
\hline & $\mathbf{N}$ & $<0.002$ & 0.004 \\
\hline & Al & - & 0.045 \\
\hline & Mo & - & 0.035 \\
\hline & $\mathbf{O}$ & 0.050 & - \\
\hline & $\mathbf{N b}$ & - & 0.019 \\
\hline & $\mathrm{Fe}$ & 0.050 & rest \\
\hline
\end{tabular}

Table 2. Mechanical properties of carbon steel and zirconium

\begin{tabular}{|c|c|c|c|c|}
\hline Material & $\begin{array}{c}\mathbf{R}_{\mathrm{e}}, \\
{[\mathbf{M P a}]}\end{array}$ & $\begin{array}{c}\mathbf{R}_{\mathrm{m}}, \\
{[\mathbf{M P a}]}\end{array}$ & $\begin{array}{c}\mathbf{E}, \\
{[\mathbf{G P a}]}\end{array}$ & $\begin{array}{c}\mathbf{A}_{\mathbf{5}}, \\
{[\%]}\end{array}$ \\
\hline Zr 700 & 143 & 300 & 100 & 31 \\
\hline P 355L2N & 402 & 511 & 210 & 27 \\
\hline
\end{tabular}

After cladding, the entire surfaces of all materials underwent ultrasonic tests in order to determine the continuity of the bond. The material for further microstructural analyses was cut-off from regions without visible traces of discontinuity; the section perpendicular to sheet surface and parallel to the detonation front motion was analyzed. A detailed description of the procedure of zirconium-carbon steel clads preparation with the use of the explosive bonding process was presented in the works of [4-5].

Five samples were 'closed' in a vacuum quartz capsule (Fig. 1a) and then they were heat treated. The heat treatment was carried out at a temperature of $600{ }^{\circ} \mathrm{C}$ by annealing the samples for 1, 10, 100, 500 and 1000 hours, followed by air-cooling. An electric muffle furnace was used for the annealing, as presented in Fig. 1b. Heat treatment conditions and sample marking are shown in Table 3.

Table 3. Annealing conditions and sample marking

\begin{tabular}{|c|c|c|}
\hline $\begin{array}{l}\text { Sample } \\
\text { designati } \\
\text { on }\end{array}$ & Condition & Treatment \\
\hline P 355 & $\begin{array}{l}\text { steel in the state } \\
\text { before bonding }\end{array}$ & $\begin{array}{l}\text { cold rolled sheet and } \\
\text { fully recrystallized }\end{array}$ \\
\hline Zr 700 & $\begin{array}{l}\text { zirconium in the } \\
\text { state before bonding }\end{array}$ & $\begin{array}{l}\text { cold rolled sheet and } \\
\text { fully recrystallized }\end{array}$ \\
\hline $\mathbf{W}$ & $\begin{array}{l}\text { condition after } \\
\text { bonding }\end{array}$ & not heat-treated \\
\hline $1 \mathrm{~h}$ & \multirow{5}{*}{$\begin{array}{c}\text { condition after } \\
\text { bonding and long- } \\
\text { lasting heating at } \\
600^{\circ} \mathrm{C}\end{array}$} & heating time 1 hour \\
\hline $10 \mathrm{~h}$ & & heating time 10 hours \\
\hline $100 \mathrm{~h}$ & & heating time 100 hours \\
\hline $500 \mathrm{~h}$ & & heating time 500 hour \\
\hline $1000 \mathrm{~h}$ & & heating time 1000 hour \\
\hline
\end{tabular}
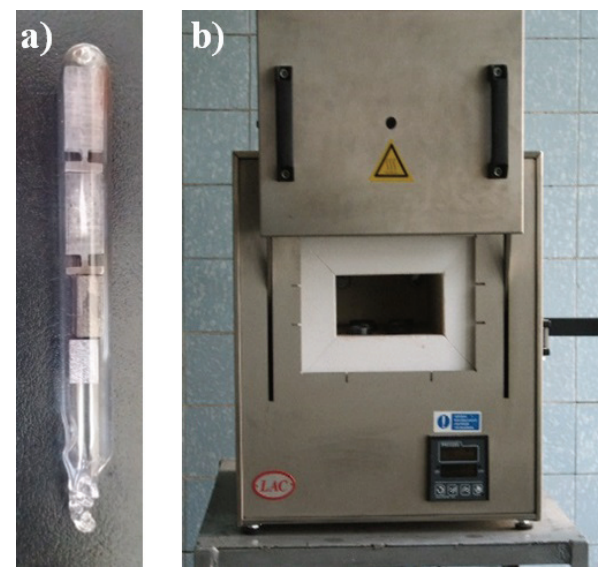

Fig. 1. Bimetal heat treating: a) the sample 'closed' in quartz capsule, b) the LMH 04/12 electric muffle furnace produced by LAC.

\subsection{Metallographic examinations}

Before the welding, the samples of $22 \times 20 \times 10 \mathrm{~mm}$ (for steel) and $3,15 \times 20 \times 10$ (for zirconium) in size were cut-off from the starting plates. These samples were marked as $\mathrm{P} 355$ and $\mathrm{Zr} \mathrm{700,} \mathrm{respectively.} \mathrm{For} \mathrm{the}$ purposes of metallographic examinations, the 
metallographic specimens were prepared from these materials. The samples were polished manually with the use of abrasive papers, with a grit size up to 600 . Then the samples were polished with a "Struers DPU2" mechanical polisher using the $\mathrm{Al}_{2} \mathrm{O}_{3}$ suspension. The final $8 \mathrm{~h}$ polishing was performed with a VibroMet vibratory polisher made by Buehler with the use of a colloidal suspension based on silicon monoxide. The final vibratory polishing stage allowed us to remove the strengthening caused by the grinding and manual polishing process. The last stage involved chemical etching with a $3 \% \mathrm{HNO}_{3}$ solution in $\mathrm{C}_{2} \mathrm{H}_{5} \mathrm{OH}$ in order to reveal the carbon steel structure and the interface between the welded plates. (There was no chemical etching of the zirconium plate since the application of very intense etching agent it is necessary to use. This damage the carbon steel and interfacial structures).

The metallographic examinations were performed with the use of an OLYMPUS IX 70 inverted microscope that was equipped with OPTI-TECH image analysis software. The detailed characterization of the interface between plates was made by measuring their basic parameters, i.e. the length ' $n$ ' and height ' $h$ ' of the wave and the surface area of the melted areas ' $\mathrm{P}_{\mathrm{i}}$ '. In all cases, the measurements were obtained based on the microstructures observed in longitudinal sections. The measurements were made according to the scheme presented in Figs. 2a-d and the quantitative share of melted areas ('RGP' coefficient) was determined on the basis of equation 1 .

$$
R G P=\frac{\sum_{i=1}^{n} P_{i}}{L},[\mu m]
$$
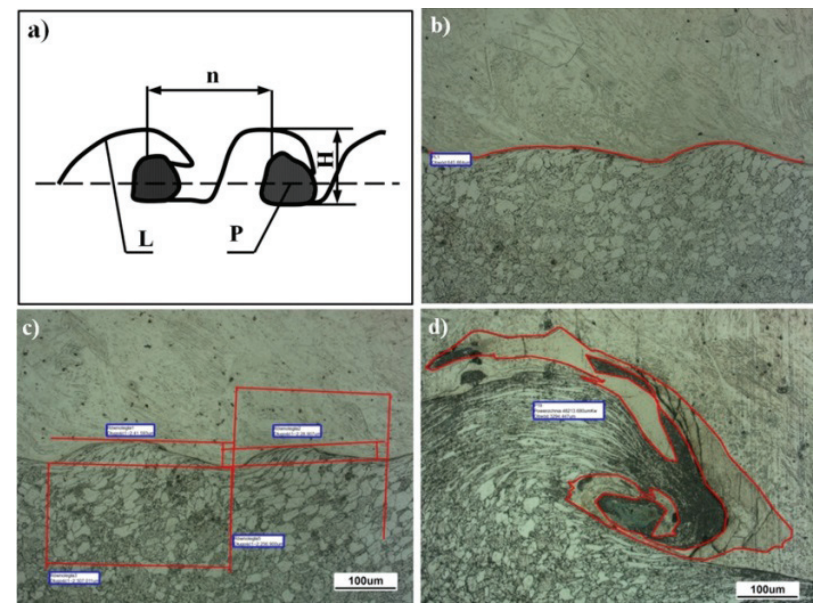

Fig. 2. a) Schematic presentation of the interface showing basic parameters of the wave:

$\mathrm{H}$ - wave height, L- length of the joining line, n- wave length, P- surface area of the melted areas.

(b-d) Examples of the microstructures showing the interfaces of different morphology:

b) flat interface, c) semi-flat interface, c) interface with melted zones, where: $P_{i}$ - is the summary surface area of melted zones.

\subsection{Microhardness tests}

Microhardness changes in layers near the interface were carried out with the use of the Vickers microhardness tester - LECO MHT Series 200. The measurements were carried out in the longitudinal section along 3 'line scans', perpendicular to the interface. Indentations were carried out for each of the joined material in the 'direction' from the interface, i.e. outside the melting zone. The first measurement was carried out $0.02 \mathrm{~mm}$ from the bottom of the wave. The tests were conducted in accordance with the guidelines provided by ISO 6507 3:1996 using 50G and 100G loads. Moreover, the microhardness measurements were done at the selected points in layers near the interface for samples 'after welding' and 'after annealing'.

\subsection{Tensile strength test}

The tensile strength tests were performed on both groups of clads (in the state after welding and annealing) on the basis of non-standard samples; their shape and dimensions are shown in Fig. 3a, whereas, schematic presentation of the sample fixing, in Fig. $3 \mathrm{~b}$.
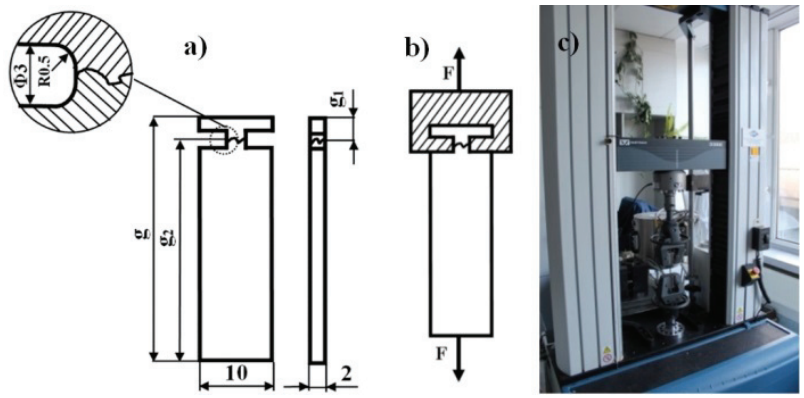

Fig. 3. a) Sample shape and dimensions for tensile test, b) sample fixing during test, c) tensile testing machine.

The measurements of the tensile strength (and the determination of $R_{m}$ value) were carried out using the tensile testing machine - Instron 3382, shown in Fig. 3c. The value of tensile strength for each of the clads was determined based on the average of three tests.

\section{Results and discussion}

\subsection{Optical microscopy observations}

The microstructure observations were carried out using optical microscopy. Fig. 4a shows the structure of $\mathrm{Zr} 700$ plate in the initial state, i.e. before the welding process. This material is characterized by an approximately equiaxial structure of oriented clusters of alpha-phase grains of a size ranged between $70 \mu \mathrm{m}$ and $170 \mu \mathrm{m}$. Fig. $4 \mathrm{~b}$ shows the structure of the base material, i.e. carbon steel P355 before the welding process. This material was characterized by the medium-sized grains: $4 \mu \mathrm{m}-11 \mu \mathrm{m}$ for pearlite and $10 \mu \mathrm{m}-20 \mu \mathrm{m}$ for ferrite. In the case of pearlite, a band of refined grains, typical of materials after hot deformation was observed. The microstructures 
of both materials before welding, show fully recrystallized states.
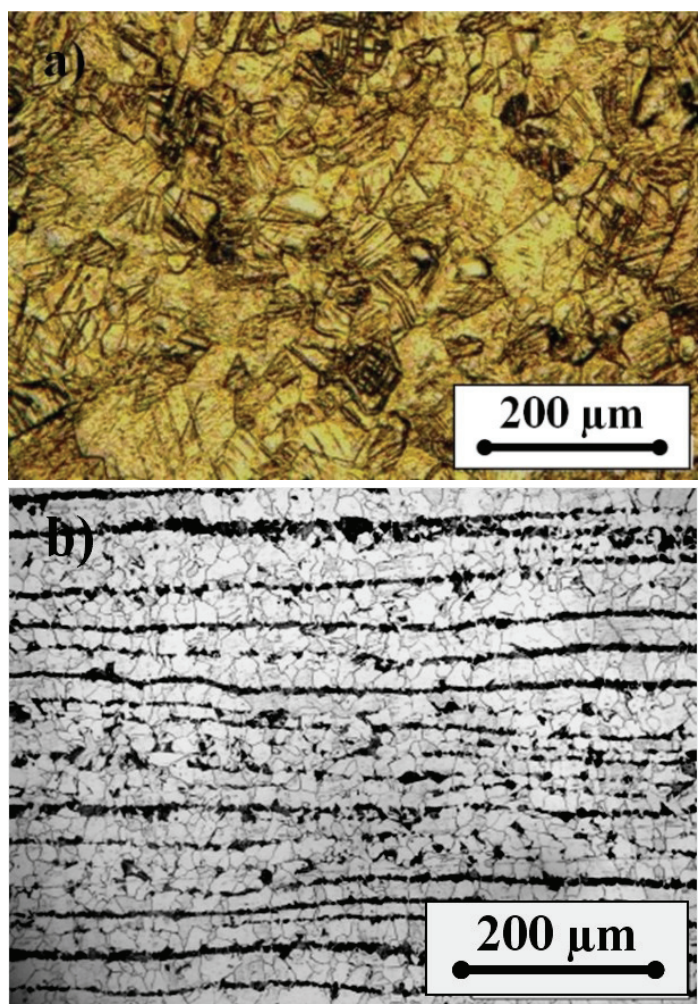

Fig. 4. Structure of materials in the initial state: a) $\mathrm{Zr} 700$, imaging by using the polarized light, b) steel P355 N2L.

The microscopic observations of clad in state 'after welding' made it possible to determine the parameters describing the interface (wave) between the welded materials. As a result of the observations and measurements, the nature of the joint was determined as 'wavy' (Fig. 5a) with wavelength $-\mathrm{n}=500 \mu \mathrm{m}$ and height $-\mathrm{H}=51 \mu \mathrm{m}$. The detailed analysis showed the occurrence of layers of flat grains and small number of melted areas of non-continuous form; they were mostly found in the vortex and on the crest of the waves, Figs. $5 \mathrm{~b}$, c. The average values of parameters describing the wave are presented in Table 4.

Table 4. Parameters describing the shape of the wave and the quantity of melted areas for clad in 'after welding' state.

\begin{tabular}{|c|c|c|c|c|c|}
\hline 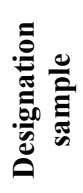 & 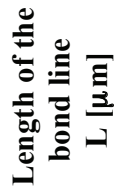 & 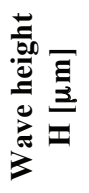 & 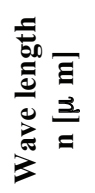 & 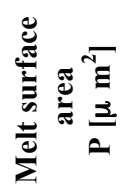 & 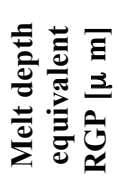 \\
\hline W & 10632 & 51 & 500 & 3366 & 0.35 \\
\hline
\end{tabular}

In layers near the interface on the steel side, a distinct plastic deformation of the ferrite and perlite grains was observed; they were situated along the direction of the detonation front movement. The strongest deformation of grains was observed on the crests of waves, where the structure of very flat grains forms a layer of $25 \mu \mathrm{m}-100$ $\mu \mathrm{m}$ in width. As the distance from the interface increases the effects connected with strong deformation progressively disappeared. It was observed that at a distance of $450 \mu \mathrm{m}-850 \mu \mathrm{m}$ from the interface only the structure of nearly equiaxed grains were observed, as also typically observed in the carbon steel plate before welding.
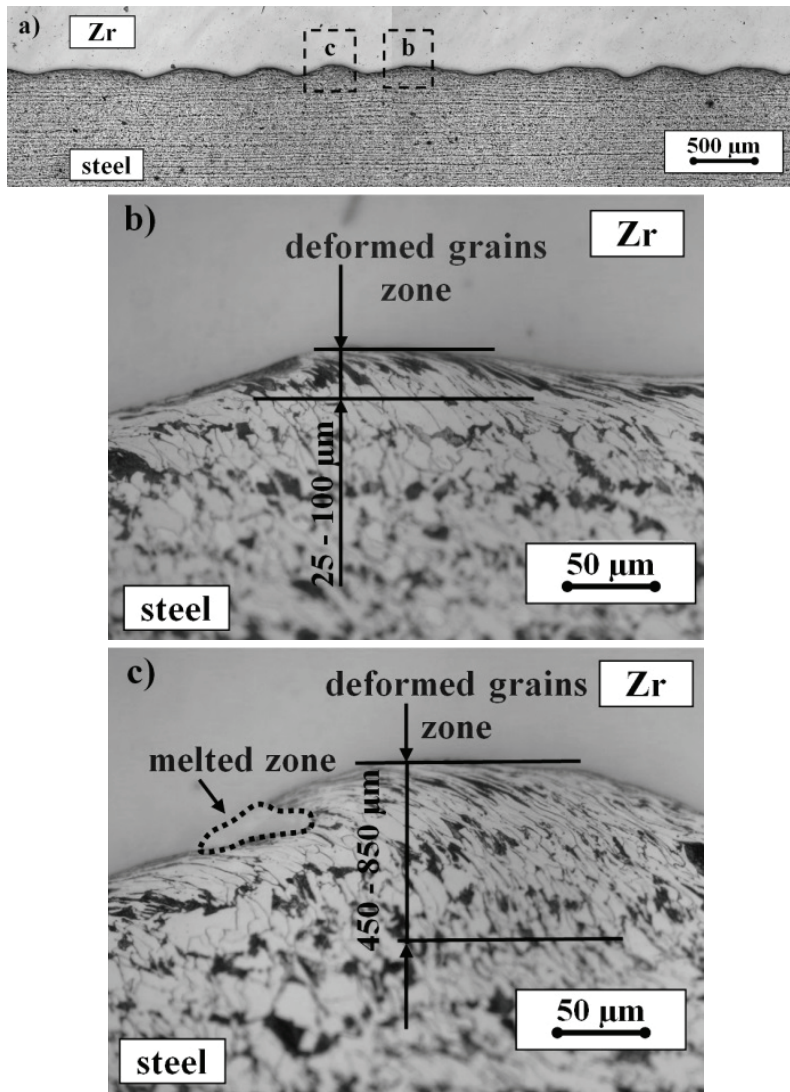

Fig. 5. Bond zone of zirconium- carbon steel bimetal: a) interface between the welded materials, b) zone of deformed grains, c) melted area

Since the heat treatment does not lead to changes of the wave parameters the analysis related to the characteristics of the weld zone was not carried out in the annealed samples. Structural changes due to the influence of temperature shows that in the case of the ' 1 h' sample, i.e. the sample annealed for 1 hour, no significant microstructural changes were observed. Essentially, the microstructure was similar to that of observed in the clad is state 'after welding' (W). Figure 6a shows ferrite and pearlite grains of strongly elongated shape (in the direction of the detonation front movement). They were identified in carbon steel plate in areas near the crest of the waves. Only small quantity of melted areas were identified; they were the privileged places of the macro-/micro- cracks nucleation, as observed in Fig. 6 a.

Recrystallized ferrite grains (the evidence of which is their equiaxial shape) and a few pearlite grains were observed in the steel plate after $10 \mathrm{~h}$ annealing (Fig. 6b). The layer of the ferrite grains (free of cementite), adjacent to the interface, can be the evidence of decarburization of this zone as a result of a long-term 
annealing at high temperature. This phenomenon intensifies for longer annealing times. In the case of
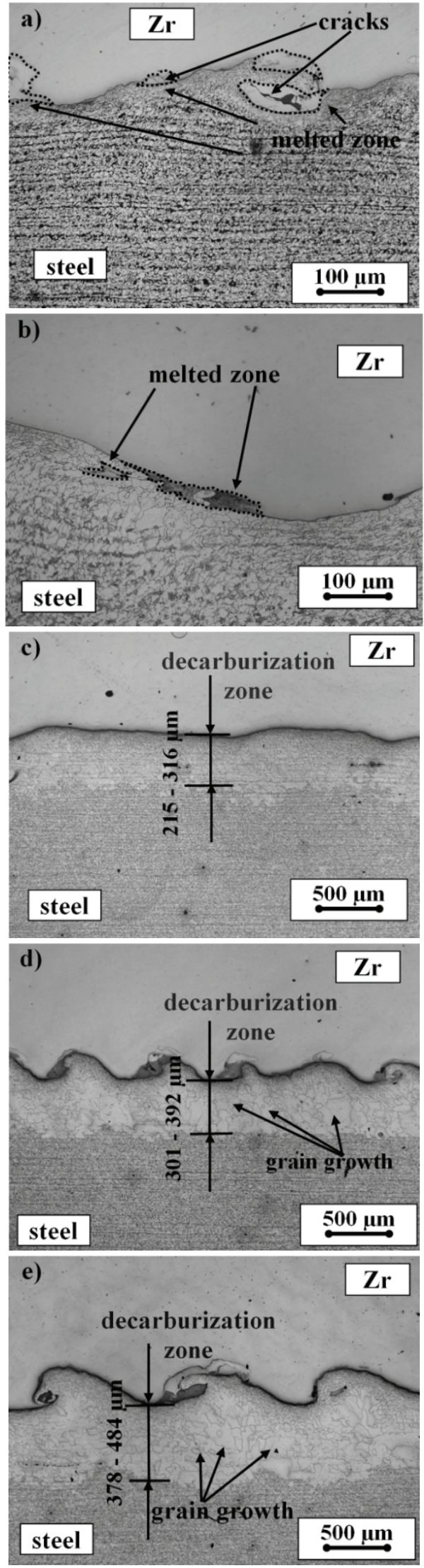

Fig. 6. Structure in the weld zone after annealing at temperature of $600{ }^{\circ} \mathrm{C}$ for: a) $1 \mathrm{~h}$, b) $10 \mathrm{~h}$, c) $100 \mathrm{~h}$, d) $500 \mathrm{~h}$, e) $1000 \mathrm{~h}$. annealing for the period of $100 \mathrm{~h}$ (100 h sample ), the width of the decarburized zone is $215-316 \mu \mathrm{m}$ (Fig. 6c). The extension of the annealing time up to 500 hours (500 $\mathrm{h}$ sample) resulted in the increase of this zone width up to 301-392 $\mu \mathrm{m}$ (Fig. 6d). As expected, the largest width of the decarburized zone was obtained for the annealing time of 1000 hours $(1000 \mathrm{~h}$ sample); in this case the width of the zone of low carbon content was ranged between $387 \mu \mathrm{m}$ and $484 \mu \mathrm{m}$ (Fig. 6e). Moreover, a significant growth of ferrite grains was observed for two longest annealing times in relation to other cases; from the point of view of strength properties this is strongly undesirable phenomenon.

\subsection{Strain hardening of the layers near the interface}

During explosive welding the plates are brought together under very high pressure and at high velocity. The deflection of the flyer plate leads to oblique collision and 'provokes' shear strains near-the-collision point/line. These phenomena contribute to the strain hardening of both materials in areas near the interface, as presented in a number of earlier works [4-8]. However, it is widely also accepted that the significant part of the kinetic energy of the jet, the impact energy and the work of plastic deformation are dissipated to heat in a very short time [6-8]. This leads to local melting and then to the zones of solidified melt formation.

The microhardness measurements made it possible to determine the changes of strain hardening, in the both near the interface (up to $0.5 \mathrm{~mm}$ ) and in areas above 3 $\mathrm{mm}$ from the interface. The results were compared with the microhardness values carried out in plates before the explosion welding. They are presented in Fig. 7.
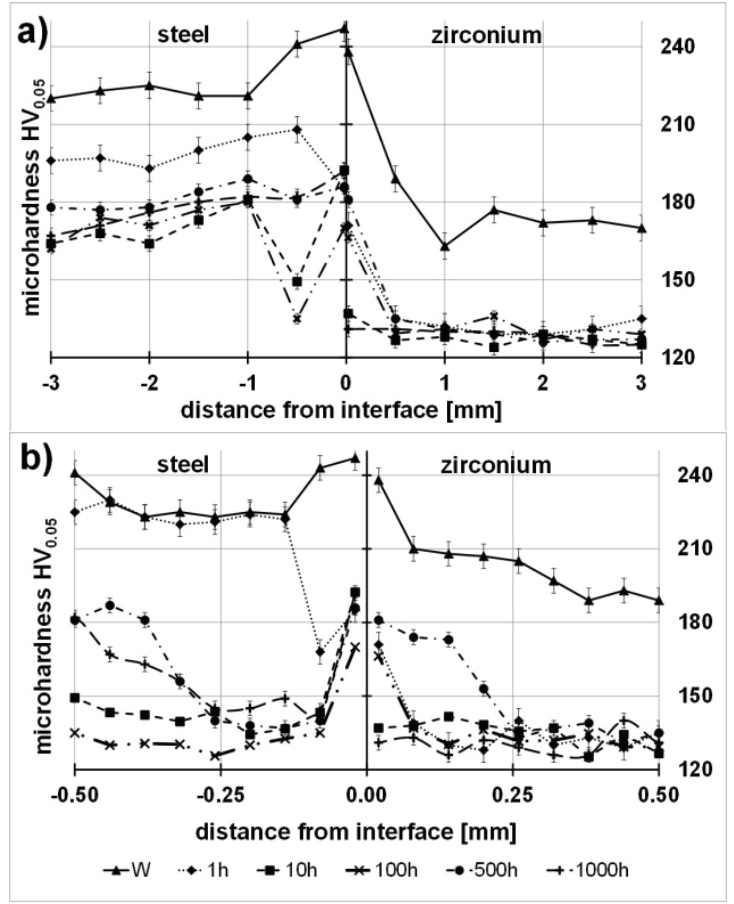

Fig. 7. Average results of the microhardness measurements in the clads after welding and after annealing at a distance of: a) 3 $\mathrm{mm}$, b) $0.5 \mathrm{~mm}$ from the interface. 
The microhardness measurements carried out in samples subjected to long-term heat treatments were compared to the measurements of bimetal hardness after welding. This opens the possibility the analyzis of the influence of heat treatment on strain hardening and strength properties of the tested samples. Fig. 7a shows the microhardness of the flyer and base plates in areas distanced $\sim 3 \mathrm{~mm}$ from the interface.

The largest microhardness (strain hardening) in both welded plates, was measured $0.02 \mathrm{~mm}$ from the interface. The microhardness decreases systematically as the distance from the interface increases and the microhardness of steel reaches its stable level $\sim 1 \mathrm{~mm}$ from the interface, as presented in Fig. 7b). The analysis of microhardness changes in the zirconium plate showed that the annealing time (at this temperature) does had any significant impact on microhardness in areas near the interface.

In the case of $1 \mathrm{~h}, 100 \mathrm{~h}$ and $500 \mathrm{~h}$ samples the microhardness of zirconium plate decreases of $\sim 30 \%$ $40 \%$, whereas in the case of $10 \mathrm{~h}$ and $1000 \mathrm{~h}$ samples the microhardness decreses of $\sim 55 \%$ in relation to the highest microhardness (value of the first measured point) in the zirconium, in state 'after bonding'. A similar level of decrease in the strengthening was observed throughout the analyzed area (up to $5 \mathrm{~mm}$ from the boundary). It is important to note that for annealed samples, the microhardness of zirconium plate was always below the microhardness measured in state 'before the welding', in the entire analysed area (175 HV).

Similar changes were observed in the carbon steel; its microhardness decreased as the annealing time increased. In the case of the shortest annealing time of $1 \mathrm{~h}$, the microhardness of layers near the interface decreased by $20 \%$ with respect to the state 'after welding'. The increase of the annealing time up to 10 hours led to the $25 \%$ decrease of microhardness, whereas in the case of sample annealed for 100 hours - up to $30 \%$ (in relation to the microhardness at this point of the material after welding). The impact of the annealing time was more evident at a distance of $0.5 \mathrm{~mm}$ from the interface; after annealing for $1 \mathrm{~h}$ the decrease of microhardness was $\sim 10 \%$ in relation to the microhardness (at this point) of the material in state 'after welding'. The increase of the annealing times up to 10 hours and $100 \mathrm{~h}$ led to the $40 \%$ and $45 \%$ decrease of microhardness, respectively, as compared to the microhardness in state 'after welding'.

The microhardness measurements in the melted areas for the sample in state 'after welding' (Fig. 8a) and after 1 hour annealing (Fig. 8b) showed that their values changes significantly. In the case of samples without annealing, the minimum microhardness was $477 \mathrm{HV}$, whereas the maximum - $896 \mathrm{HV}$. The maximum value of microhardness in zirconium plate is nearly 4 times greater than the most strain hardened layers of steel plate ( $247 \mathrm{HV})$. Annealing for shorter annealing times (1h and 10h) did not cause significant changes in the microhardness of the melted areas with respect to the microhardness of sample 'after welding'. As an example, the microhardness of the sample annealed for $1 \mathrm{~h}$ ranged between 354 and $1053 \mathrm{HV}$ (Fig. 8b).
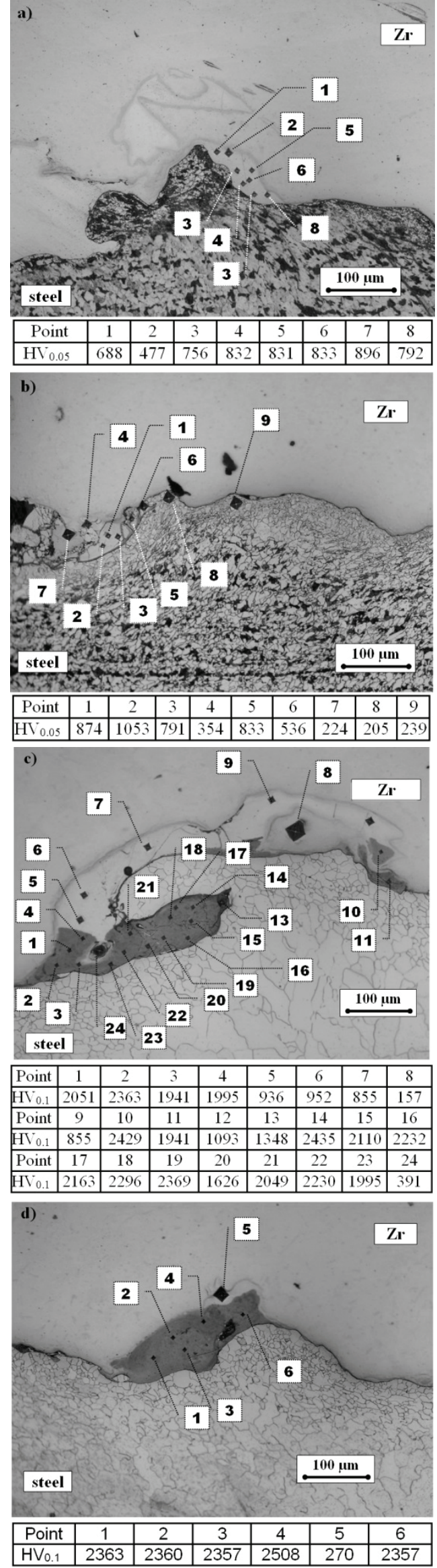

Fig. 8. Microhardness in the melted areas of zirconium-carbon steel clad: a) state after welding and state after annealing at $600^{\circ} \mathrm{C}$ for: b) $1 \mathrm{~h}$, c) $100 \mathrm{~h}$, d) $500 \mathrm{~h}$. 
Long annealing times (i.e. $100 \mathrm{~h}$ and $500 \mathrm{~h}$ ) resulted in over 1.5 times larger values of microhardness in the melted areas relative to the state after welding. The maximal value of microhardness in the melted areas for the 100h sample was $2436 \mathrm{HV}$ (Fig. 8c, point 14) whereas for the 500h sample reached $2508 \mathrm{HV}$ (Fig. 8d, point 4).

\subsection{Strength properties}

The tensile test was carried out on samples in states 'after welding' and 'after annealing' for determination of the tensile strength $\left(\mathrm{R}_{\mathrm{m}}\right)$ od the clad; it makes possible to compare changes in the mechanical properties. Fig. 9 shows the average values of three tests for each case.

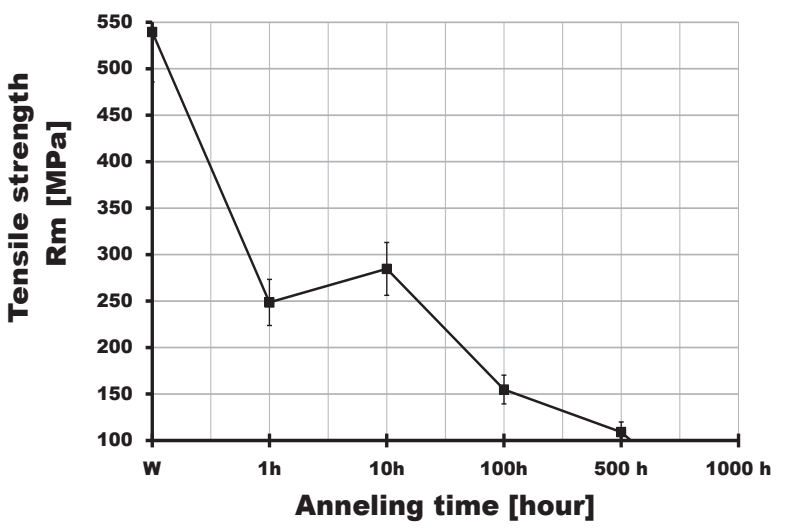

Fig. 9. Impact of the annealing time on the tensile strength of zirconium - carbon steel clad.

The tests show that the annealing time significantly affects the value of the tensile strength $\left(R_{m}\right)$ of the clad. The average strength of the bimetal after welding (sample W) was $537 \mathrm{MPa}$. This value confirms high mechanical properties of the joint, which are similar to the properties of steel before welding (Table 4). The annealing of the clads at a temperature of $600^{\circ} \mathrm{C}$ for $1 \mathrm{~h}$ and $10 \mathrm{~h}$ ( $1 \mathrm{~h}$ and $10 \mathrm{~h}$ samples) leads to the strength decrease of approximately $50 \%$ up to $248 \mathrm{MPa}$ and 284 $\mathrm{MPa}$, respectively (Fig. 9). This results from the microhardness decrease due to microstructural changes caused by the recrystallization of severely deformed layers near the interface. The strength decrease of $\sim 70 \%$ was observed in the case of the $100 \mathrm{~h}$ sample annealed for the 100 hours, and $\sim 85 \%$ decrease in the case of annealing time of 500 hours $(500 \mathrm{~h}$ sample), in relation to the microhardness of the sample after the welding process. The strength test was not carried out for the sample annealed for the $1000 \mathrm{~h}$, since the tested material undergo delamination during heating. Such low strength properties for the longest annealing times are associated with a significant growth of grains in the layers near the interface and almost complete decarburization of this zone on the side of the carbon steel plate.

\section{Conclusions}

The obtained results make it possible to draw the following conclusions:
- The correct selection of explosion welding process parameters, i.e. detonation velocity and initial distance between the plates being welded, makes it possible to obtain a corrugated interface with a high amplitude and length of the wave.

- Brittle and hard areas of solidified melt were identified in layers near the interface, but their participation in the joint did not exceed the limit values of the 'correct' RPG coefficient, which is assumed to be $10 \mu \mathrm{m}$.

- The microhardness of the melted areas, which occur near the interface, was always several times higher that the one of the most strain hardened layers of both sheets. Brittle nature of the melted zones contributes to the occurrence of cracks, which are visible during the microscopic examination. For longer annealing times $(100 \mathrm{~h}$ and $500 \mathrm{~h})$ more than 1.5 times increase of the microhardness of the melted zone was observed.

- The heat treatment significantly reduces the strain hardening of layers near the interface, and the largest changes were observed in the carbon steel plate.

- The annealing induces significant microstructural changes in layers near the interface. Shorter annealing times, i.e. $1 \mathrm{~h}$ and $10 \mathrm{~h}$, have a positive impact on the mechanical properties due to the formation of small (equiaxed) recrystallized grains. In the case of longer annealing times $(100 \mathrm{~h}$ and $500 \mathrm{~h}$ ), mechanical properties decreases; there is observed a significant growth some of the grains and the decarburization of steel plate in layers near the interface.

- Microstructural changes occurring during the annealing affect the mechanical properties of the tested clad. An extended annealing time causes a systematic decrease of the tensile strength in relation to the values measured in the state 'after welding'.

The presented results have allowed to assess the effect of time and temperature on the heat treatment on the tensile strength, microhardness and microstructure of zirconium / steel bimetal.

\section{Acknowledgment:}

This work was partially supported by the Polish Ministry of Science and Higher Education, project no: NN507 457839.

\section{References}

1. B. Crossland, Explosive Welding of Metals and its Application, (Clarendon Press, UK, 1982)

2. H. Dyja, A. Maranda, R. Trębiński, Technologie wybuchowe w inżynierii materiałowej, (Wyd. Wydz. MiIM Pol. Częstoch. 2001)

3. W. Walczak, Zgrzewanie wybuchowe metali i jego zastosowanie, (WNT, Warszawa 1989)

4. M. Prażmowski, Arch. Metall. Mater. 59, 1137-1142 (2014)

5. M. Prażmowski, H. Paul, Arch. Metall. Mater. 57, 1201-1210 (2013) 
6. H. Paul, T. Baudin, F. Brisset, M. Prażmowski, Mat. Sci. Engin. 82 (2015)

7. H. Paul, J. Morgiel, T. Baudin, F. Brisset, M. Prażmowski, M. Miszczyk, Arch. Metall. Mater. 59, 1129-1136 (2014)

8. H. Paul, J. Morgiel, M. Faryna, M. Prażmowski, M. Miszczyk, Int. J. Mat. Res. 106, 782-792, (2015)

9. M. Prażmowski, D. Rozumek, H. Paul, Engn. Failure Anal. 75, 71-81 (2017)

10. M. Acarer, B. Gulenc, F. Findyk, Mater. Des. 24, 659-664 (2003)

11. P. Nieslony, P. Cichosz, G.M. Krolczyk, S. Legutko, D. Smyczek, M. Kolodziej, Measurement 78, 129137 (2016)

12. P. Nieslony, G.M. Krolczyk, K. Zak, R.W. Maruda, S. Legutko, Prec. Eng. - J. Int. Soc. Prec. Eng. Nanotechnol. 47, 104-110 (2017)

13. T.Z. Blazynski (ed.), Explosive welding, forming and compaction, (Applied Science Publishers, London and New York, 1983)

14. M. Prażmowski, H. Paul, F. Żok, Arch. Metall. Mat. 59, 1143-1149 (2014)

15. F. Findik, R. Yilmaz, T. Somyurek, Sci. Res. Essays 6, 9, 4141-4151 (2011)

16. C. Prothe, S. Pauly, C. Toth, Corrosion Solutions Conference 2005, 53-59.

17. M. Raudbari, A. Mehdipoor, R. Azarafza, Int. Res. J. Appl. Basic Sci. 7, 10, 687-692 (2013)

18. T. Tetsui, Y. Miura, Tech. Rev. 1, 1-9 (2002)

19. J. Małecka: Int. J. Mat. Res. 9, 104, 885-891 (2013) 